\title{
De FHC a Lula \\ Uma década de política externa (1995-2005)
}

Paulo Fagundes Vizentini*

\section{Introdução}

A política externa brasileira conheceu notável evolução nos últimos dez anos, que compreendem os dois mandatos do presidente Fernando Henrique Cardoso e a primeira parte do governo Luiz Inácio Lula da Silva. Este período teve inicio no auge do modelo neoliberal da globalização, com a idéia de que o país deveria se inserir no novo cenário internacional numa perspectiva de ampla abertura aos fluxos comerciais e financeiros. Mas a isso, seguiram-se a instabilidade financeira internacional, o colapso da Argentina e os atentados de 11 de setembro de 2001, que ensejaram a guerra ao terrorismo da administração Bush. Uma inflexão foi esboçada por FHC ao longo do seu segundo mandato, formulando, ainda que timidamente, uma postura mais crítica em relação à globalização e a Alca, bem como uma iniciativa de integração sul-americana. O governo Lula deu nova dimensão à diplomacia brasileira, reforçando a atuação internacional do país, especialmente em relação à América do Sul, aos organismos internacionais e às potências emergentes do Sul. Neste sentido, o presente artigo visa analisar esta trajetória em seus fundamentos e perspectivas.

Professor de História e Coordenador do Núcleo de Estratégia e Relações Internacionais (Nerint) da Ufrgs. Professor Convidado nos cursos de pós-graduação da FAPA. Pós-Doutorado em Relações Internacionais pela London School of Economics. E-mail: paulovi@ifch.ufrgs.br.

\begin{tabular}{|l|l|l|l|l|l|}
\hline Civitas & Porto Alegre & v. 5 & n. 2 & jul.-dez. 2005 & p. 381-397 \\
\hline
\end{tabular}




\section{A diplomacia de Fernando Henrique Cardoso: o projeto inicial (1995-1998)}

Em 1994, o Plano Real permitiu a Fernando Henrique Cardoso uma vitória relativamente fácil sobre o candidato da esquerda, hoje presidente, Luiz Inácio Lula da Silva. FHC retomou o projeto neoliberal de inserção no processo de globalização econômica iniciado por Collor de forma mais bem articulada e com estabilidade na execução do processo. Luiz Felipe Lampreia foi nomeado ministro das Relações Exteriores e Pedro Malan, ministro da Fazenda, este último um homem completamente identificado com o programa do FMI e do Banco Mundial, expresso no Consenso de Washington. O presidente representava o novo político dos anos 1990: jovial, contra a "política tradicional", poliglota e intelectualizado.

No plano especificamente diplomático, Fernando Henrique habilmente esvaziou o Itamaraty de suas funções, uma vez que este órgão representava um foco de resistência do projeto nacional-desenvolvimentista. FHC transferiu as atribuições econômicas do MRE para o Ministério da Economia e, ao mesmo tempo, assumiu pessoalmente sua dimensão política com a introdução da diplomacia presidencial. As linhas de ação prioritárias foram as seguintes: avançar no caminho da integração regional, aprofundando o Mercosul; estímulo à estratégia de diversificação de parceiros nas relações bilaterais; ação junto às organizações econômicas multilaterais, em especial à $\mathrm{OMC}$, e concentrar esforços para elevar a posição de potência internacional do Brasil, tornando-se um membro permanente do Conselho de Segurança da ONU, usando, para tanto, de argumentos como tamanho territorial, contingente populacional e seu status na organização.

O novo presidente, internamente, intensificou o processo de privatizações das grandes e eficientes empresas públicas (aeronáutica, petroquímica, siderúrgica e telecomunicações) sem se preocupar com as empresas privadas e os custos sociais. Adotou também o hábito de não se referir ao Brasil como um país subdesenvolvido, contudo não se pode desconsiderar que tal condição ultrapassava a questão conceitual, pois a estabilização monetária foi fundada sobre o endividamento externo e o Plano Real acabou com o histórico superávit comercial nacional. 
O caráter da política externa desenvolvida no governo de FHC sinalizava para a instauração de novos projetos e parcerias, sem definir claramente o paradigma estratégico pelo qual estava se orientando. FHC, como ministro das Relações Exteriores (outubro de 1992 a maio de 1993), deu início à substituição da ênfase na América Latina pela América do Sul, delimitando uma nova esfera geográfica da política regionalista. Essa diretriz teve uma dimensão prática muito importante na agenda diplomática sul-americana e o Mercosul passou a ser o núcleo desta estratégia.

Em 1994, o Mercosul adquiriu personalidade jurídico-institucional como união aduaneira para os países membros e sua vertente política passou a buscar novos parceiros. No período 1991-1997, o comércio intrazona apresentou taxas aceleradas de crescimento, afirmando a dimensão econômico-comercial do bloco, mas também avançou no caráter político-estratégico, para aprofundar os mecanismos de reparos e decisões conjuntas (destacando-se a "cláusula democrática" do bloco, decisiva na consolidação dos regimes democráticos na região, sobretudo nas crises paraguaias). Todavia, estes aspectos não se completaram, levando, a partir das crises de 1999, ao esgotamento do Mercosul em sua forma até então vigente.

Um fator de pressão sobre o Mercosul foi a proposta da criação de uma Área de Livre Comércio das Américas (Alca) e a postura política da Argentina na era Menem/Cavallo, que buscava um alinhamento com os EUA e adotou um modelo econômico de profundo viés neoliberal, com dolarização e privatizações. ${ }^{1}$ Em Dezembro de 1994, o Brasil aceitou, com relutância, a proposta de iniciar negociações para a criação da Alca, com base na avaliação de que, caso optasse por obstruir o processo, se encontraria em posição isolada no continente e confrontando diretamente os EUA. Assim, o posicionamento brasileiro sinalizou para a defesa constante do multilateralismo e nas relações econômicocomerciais e na defesa dos planos de integração regional, tentando sempre ganhar tempo em relação à Alca, mas sem opor-se frontalmente a ela. A direção da política externa brasileira indicava uma orientação globalista e uma melhora contínua no relacionamento com os EUA.

Paralelamente, uma série de contenciosos com este país foram solucionados, com uma clara demonstração de limpeza da agenda internacional: adesão ao TNP (Tratado de Não-Proliferação Nuclear), ao Mctr (Regime de Controle de

\footnotetext{
Que, posteriormente, será responsável pelo colapso da Argentina.
} 
Tecnologia de Mísseis) e ao Grupo dos Supridores Nucelares (NSG), o que implicou na aceitação das demandas das grandes potências. Entretanto, poucos foram os ganhos com estas políticas no campo estratégico, político ou econômico. No cenário internacional pós-Guerra Fria, a política norte-americana apresentou um caráter agressivo no setor comercial, o que denotou um balanço deficitário para o Brasil. Além disso, o processo da Alca sofreu um revés, devido ao constante insucesso do presidente Clinton em obter a autorização do Congresso para acelerar sua implementação (mecanismo conhecido por fast track).

Paralelamente, as relações bilaterais continuaram a ser marcadas pela busca do multilateralismo, a chamada postura de global trader. O Brasil manteve seus contatos com a União Européia, através de negociações bilaterais e pelo Mercosul, havendo ainda aproximações com Índia e Malásia. Ao lado das crescentes relações econômicas, desenhou-se a possibilidade do estabelecimento de parcerias estratégicas com China, Índia e Rússia, envolvendo a cooperação nuclear, aeroespacial e o exercício de uma grande diplomacia voltada para a estruturação de um sistema internacional multipolar, como forma de contornar uma nova unilateralidade norte-americana. O problema é que o Brasil não cumpriu muito dos itens acordados, ou abandonou seus aliados ao primeiro sinal de problemas, por exemplo, denunciou, unilateralmente, o acordo de cooperação tecnológica com a Índia quando este país realizou testes atômicos. $\mathrm{Na}$ verdade, o Brasil cumpria apenas os compromissos com os países do Primeiro Mundo e com os organismos internacionais.

Em 1997, FHC conseguiu aprovar a emenda da reeleição e venceu o pleito com base no Plano Real e no controle da inflação. Enquanto os produtos expurgados dos índices inflacionários subiam (como os consumidos pela classe média), os bens básicos eram importados a preços baixos, mantendo estável a cesta básica. Contudo, durante a campanha, as dificuldades começaram a se manifestar: a crise asiática de 1997 e a russa de 1998 criaram uma nova realidade nas finanças mundiais que teve como conseqüência para o país uma enorme fuga de capitais, que foi de 50\% durante a campanha e, se tivesse ocorrido segundo turno, a reeleição poderia ter sido ameaçada. A crise financeira e a cambial de Janeiro de 1999 e a possibilidade de retrocesso de alguns objetivos alcançados pelo governo na estabilização monetária, levaram o governo a desvalorizar o Real como forma de equilibrar as contas. Desta forma, o segundo mandato de FHC se iniciou sob a crise e a necessidade de mudança, com impactos sobre a diplomacia brasileira. 


\section{A inflexão da diplomacia de FHC: a crise do modelo (1999-2002)}

Assim, todo o cenário mundial em que o governo baseara sua inserção internacional começou a se desarticular. $\mathrm{O}$ discurso da adesão subordinada à globalização neoliberal foi substituído pela crítica à "globalização assimétrica". Também em 1999, o próprio Mercosul passou por um momento extremamente delicado: observou-se um desequilíbrio entre Brasil e Argentina, o que também afetou a relação com os demais membros e os países associados. Entre 1998 e 1999, o bloco perdeu a dinâmica. Esgotou-se a etapa dos ganhos fáceis com a integração, característicos da fase inicial de expansão de comércio, em decorrência da redução tarifária automática. A partir deste momento, o ministro da Economia argentino Domingos Cavallo passou a investir duramente contra o Mercosul e sua Tarifa Externa Comum (TEC), apostando na integração hemisférica proposta pelos EUA, a Alca, que nesta conjuntura era considerada em ascensão. A Alca e o Mercosul pareciam ser, neste contexto, opções excludentes. Pouco tempo depois, a Argentina sofreu um colapso econômico e político que evidenciou os problemas deste modelo neoliberal. Simultaneamente, o Brasil tentava arrastar as negociações para ganhar tempo, mas a estratégia protelatória tinha limites, pois o país também negociava na OMC (Organização Mundial do Comércio) e com a União Européia (UE).

Diante deste cenário, afastando-se de seu rumo inicial de abertura pouco cuidadosa e negociações sem as devidas compensações, em seus dois últimos anos a diplomacia do presidente FHC desenvolveu uma significativa agenda para a América do Sul, como forma de articular uma alternativa à crise do Mercosul e manter o processo de integração. FHC procurou recuperar certa margem de autonomia frente aos EUA a partir do início da administração Bush. Em uma situação adversa, a diplomacia brasileira resolveu dar um salto à frente.

Especificamente com relação ao Mercosul, deve-se destacar que suas crises resultaram do fato de os governos dos quatro países-membro, não aproveitarem a situação favorável de 1991-1997 para lançar políticas efetivas no campo tecnológico e macroeconômico para tornar suas empresas competitivas, permitindo, inclusive, a desnacionalização de ramos estratégicos, cujo controle seria vital para efetuar-se um salto qualitativo. Além disso, negligenciaram a importância da ampliação dos próprios mercados internos que, se ampliados por reformas sociais, lhes proporcionariam uma economia de 
escala, potencializando o desempenho de suas empresas. Faltou, enfim, um projeto de desenvolvimento conseqüente que fomentasse a produção local. Porém, estas dificuldades não impediram o seu relançamento na nova fase da diplomacia brasileira.

Em agosto de 2000, quando muitos acreditavam que qualquer integração latino-americana havia perdido sentido e a Alca era a única solução, o presidente Fernando Henrique Cardoso convocou a I Reunião de Cúpula dos Países Sul-Americanos, em Brasília. A realização da Cúpula de Brasília foi simultânea ao lançamento do Plano Colômbia, plano de ajuda no combate ao narcotráfico, oficializado pela Casa Branca em 31 de agosto de 2000. As iniciativas explicitaram duas tendências opostas, mas associadas, que vinham se desenvolvendo na América do Sul. Tratava-se de duas respostas distintas ao fim da estabilidade político-econômica do início da década de 1990, a norte-americana e a brasileira.

Paradoxalmente, a reação à crise do Mercosul centrou-se na ampliação da integração para toda a América do Sul, sinalizando a possível realização da idéia da Alcsa (Área de Livre Comércio Sul-Americana) lançada em 1993. Contudo, devido à conjuntura adversa, este encontro histórico esbarrou na impossibilidade de avançar acordos comerciais, optando por um caminho alternativo de fortalecimento. Assim, o encontro definiu uma série de medidas práticas e consensuais, sendo a principal delas a integração física da infra-estrutura dos países sul-americanos, que historicamente haviam estado de costas uns para os outros e de frente para o mar. As redes de transporte, telecomunicações, energia, gasodutos e oleodutos, entre outras, seriam interligadas, gerando condições materiais para a integração das economias.

Em 2002, realizou-se a II Cúpula Sul-Americana em Guayaquil, Equador, dando seqüência ao processo que previa, entre outras coisas, o estabelecimento de uma associação entre os dois grandes projetos de integração sulamericanos, o Mercosul e a Comunidade Andina. O presidente Fernando Henrique Cardoso, que discursou em nome dos presentes, criticou a atitude protecionista dos países do Primeiro Mundo no campo comercial, expressou suas dúvidas sobre a viabilidade da Alca nas circunstâncias então vigentes e lamentou a falta de resultado nas negociações Mercosul-União Européia. Além de criticar a política norte-americana, embora sem se referir formalmente aos EUA, o discurso de Fernando Henrique Cardoso pregou a necessi- 
dade desta associação entre o Mercosul e a Comunidade Andina. Neste contexto, países como a Colômbia eram refratários à idéia, enquanto a Venezuela desejava uma adesão plena ao Mercosul, o que era inviável individualmente, pois este país já pertencia ao outro bloco. Mas, o protecionismo norteamericano e a ausência de ajuda à Argentina, após o colapso financeiro deste país, aliados à instabilidade econômica internacional, deram novo impulso a este projeto.

Concretamente, durante a realização da $23^{\mathrm{a}}$ Cúpula do Mercosul, realizada em Brasília dias 5 e 6 de dezembro, o que foi conseguido foi apenas um acordo de complementação econômica com a Comunidade Andina e o compromisso de dar continuidade à integração entre os dois blocos. No tocante especificamente ao Mercosul, foi assinado um acordo facilitando aos cidadãos a fixação de residência e a possibilidade de trabalhar nos demais países do bloco. As grandes pendências foram adiadas para 2003, ou seja, para o novo governo. Assim, o Grand Finale desejado pelo presidente FHC acabou não se concretizando, mas reafirmou-se o objetivo de levar adiante o projeto inicial de transformar o Mercosul numa União Aduaneira.

De qualquer maneira, o estabelecimento de vínculos entre o Mercosul e a Comunidade Andina, com vistas à formação futura de uma área de livre comércio, criou novas perspectivas para a integração regional e para as negociações da Alca. A economia brasileira necessita do espaço sul-americano para seu parque industrial, enquanto, por outro lado, busca manter seus vínculos externos múltiplos, quase igualmente distribuídos entre o Nafta, a União Européia, a Ásia oriental e a América do Sul. Para os demais países da região, o Brasil oferece boas perspectivas. Se as promessas são bem mais modestas que as da Alca, parecem ser bem mais viáveis, duradouras e mutuamente vantajosas. Quanto às negociações da Alca, a posição sul-americana seria reforçada. Por fim, esta iniciativa parecia indicar uma continuidade desejável entre as políticas externas do governo que se encerrava e do que se iniciava no Brasil.

A eleição de Lula transcorreu com grande facilidade, o que evidencia uma espécie de pacto de continuidade com o governo que se encerrava. Mas a vitória eleitoral do presidente não foi acompanhada pela conquista de estados importantes, e o novo governo não possuía maioria parlamentar, obrigando-o a promover um pacto amplo com outros partidos, o que viria a diluir ainda mais o 
projeto governamental e a deixar as forças de esquerda sem coesão ou orientação. Especificamente em relação à diplomacia de FHC, ela foi dirigida, essencialmente, em direção à agenda globalizadora, embora certa margem de recuo tenha sido mantida, especialmente devido à integração regional. Fortes boatos sobre a intenção do ex-presidente Cardoso de vir a ocupar o cargo de secretário geral da ONU ainda estão por se confirmar, mas não seriam infundados e explicariam muitas das atitudes de sua política externa.

\section{A política externa de Lula (2003-2005): uma agenda afirmativa}

A eleição de Lula causou muita apreensão dentro e fora do Brasil a respeito de como seria a atuação do novo governo. Muitos esperavam um comportamento internacional baseado em visões ideológicas e um presidente despreparado. Mas o que se viu foi uma diplomacia dotada de sentido tático-estratégico, de visão de longo alcance, cujos elementos serão aqui analisados. Como vimos, embora o atual curso da política externa brasileira tivesse início já em meados do governo FHC, não houve, naquele momento alterações concretas significativas. O ex-presidente não possuía a vontade e a base política para uma mudança que ultrapassasse um tímido discurso crítico. A posse de Lula mudou esta situação e, neste período inicial de governo, a política externa brasileira tem conhecido notável desenvolvimento e protagonismo, superando muitas expectativas.

Para a concretização dessa estratégia, as relações internacionais do governo Lula são dotadas de três dimensões: uma diplomacia econômica, outra política e um programa social. A primeira dimensão é realista, a segunda de resistência e afirmação e a terceira propositiva. Trata-se de um projeto amadurecido por mais de uma década, e não uma política voluntarista, e está adequada à correlação de forças existente no país e no mundo.

Em relação ao primeiro aspecto, é necessário manter abertos os canais de negociação com o Primeiro Mundo, obtendo recursos (investimentos e tecnologia), negociando a dívida externa e sinalizando que o governo deseja cumprir os compromissos internacionais, sem nenhuma ruptura brusca. A diplomacia política, por sua vez, representa um campo de reafirmação dos interesses nacionais e de um verdadeiro protagonismo nas relações internacionais, com a intenção real de desenvolver uma "diplomacia ativa e afirmativa", encerrando uma fase de estagnação e esvaziamento. 
O governo Lula devolveu ao Itamaraty a posição estratégica que anteriormente ocupara na formulação e execução da política exterior do Brasil, pois, no governo anterior, FHC dominara a parte política ("diplomacia presidencial"), e o ministro Malan, a agenda econômica internacional, restando ao Ministério das Relações Exteriores apenas a parte técnico-burocrática das negociações e o recebimento das críticas. A nomeação do Embaixador Celso Amorim para o Ministério das Relações Exteriores, diplomata de carreira, que já foi Chanceler durante o governo Itamar Franco, constituiu um sinal de que a política externa manteria seus rumos.

Finalmente, o projeto interno do governo Lula também tem um significativo impacto internacional na medida em que suas propostas sociais vão ao encontro da agenda que busca corrigir as distorções criadas pela globalização, centrada apenas em comércio e investimentos livres. A campanha de combate à fome, representa o elemento simbólico que sinaliza a construção de um modelo sócio-econômico alternativo, respondendo à crise da globalização neoliberal. Medidas anunciadas como a revalorização do mercado doméstico e da capacidade de poupança interna, de uma economia de produção e de combate aos fatores internos que debilitam uma ação internacional mais qualificada (como desigualdade social, desemprego, criminalidade, fraqueza e desordem administrativa e caos fiscal), são evidências da construção de tal projeto. As políticas sociais, energéticas, urbanas, fundiárias e produtivas representam uma vontade política neste sentido. Paralelamente, o carisma do presidente, parece haver sintetizado em sua figura franca e simples as características que o mundo admira no Brasil. Isso tem permitido que Lula desenvolva uma intensa agenda internacional como porta-voz deste projeto.

O Brasil age com otimismo e vontade política, criando constantemente fatos na área internacional. Anteriormente tínhamos uma baixa auto-estima, pois os governos Collor e Cardoso viam o país como atrasado em relação aos ajustes demandados pelos países ricos. Agora, ao contrário, o país se considera protagonista de mesmo nível, com capacidade de negociação e portador de um projeto que pode, inclusive, contribuir para inserir a agenda social na globalização. Em lugar de vagos discursos contestatórios e de uma obediência prática, o país tem proposto medidas e concretizado as que estão ao seu alcance. Sim, porque havia uma margem de manobra, embora limitada, que poderia, mas não foi aproveitada nos anos 90. A ênfase da era FHC foi invertida, o que implica uma inflexão significativa em termos de política externa. 
Em termos práticos, o governo brasileiro suplantou a passividade do anterior e buscou alianças fora do hemisfério como forma de ampliar seu poder de influência no âmbito internacional a partir da mencionada postura ativa e pragmática. Como principal prioridade da agenda percebe-se a reconstrução do Mercosul e a integração sul-americana, criando um espaço para a liderança brasileira. Além disso, a solidariedade com a África também é central, pois associa princípios éticos e interesse nacional. A intenção de aprofundar as relações (e estabelecer uma "parceria estratégica") com potências emergentes como China, Índia, Rússia e África do Sul, entre outras, ao lado do estabelecimento de uma associação entre o Mercosul e a União Européia e da valorização das organizações internacionais (especialmente a ONU), ao lado das vantagens econômicas que propicia, sinalizam a intenção de contribuir para o estabelecimento de um sistema internacional multipolar. Dessa forma, o princípio de democratização das relações internacionais foi invocado explicitamente.

Todas essas iniciativas apontam para a tentativa de criar um equilíbrio em relação ao que permanece sendo, em função da globalização, a principal dimensão de inserção internacional: as relações com as grandes potências (especialmente os EUA) e com o capital estrangeiro. Sem fugir a essa realidade, iniciou-se a construção de um espaço maior de barganha e de uma alternativa global, com o Brasil dando uma contribuição proporcional ao seu peso internacional. Na prática, isto significou que o Itamaraty, em lugar de concentrar-se na tentativa de cooperação com países em relação aos quais somos secundários e a mercados grandes, mas saturados, buscou os espaços não ocupados, exercitando uma diplomacia high profile. Com essas credenciais, o presidente brasileiro abriu a Assembléia Geral da ONU em Nova Iorque, evento que teve uma participação recorde de líderes em 2003.

Uma das primeiras ações foi na Venezuela, quando o Brasil encaminhou ajuda ao país vizinho que enfrentava uma greve geral de quase dois meses mantida pela oposição contra o governo do presidente Hugo Chávez. Além disso, propôs a criação de um Grupo de Países Amigos da Venezuela, em apoio à mediação da OEA (o grupo incluiu Brasil, EUA, Chile, México, Portugal e Espanha). A proposta brasileira gerou críticas da oposição daquele país e certo desconforto por parte dos EUA. Washington foi surpreendida pela agilidade da diplomacia brasileira e procurou assumir a iniciativa como forma de minimizar a emergente liderança sul-americana do Brasil. 
É necessário enfatizar que o Brasil possui relações intensas e amistosas com a Venezuela, independente de que governo esteja no poder em qualquer um dos dois países. Acordos sobre controle de fronteira, complementação econômica, integração das redes de transporte e de energia foram estabelecidos entre Caracas e Brasília já em 1994, durante os governos Itamar Franco e Rafael Caldera (Protocolo La Guzmania). Vale lembrar que, há mais ou menos dois anos, quando da greve dos petroleiros e da ocupação de refinarias, o ex-presidente FHC enviou o exército para manter os serviços funcionando. Desta forma, a ajuda brasileira não representa nenhum tipo de "solidariedade esquerdista" ou intromissão em assuntos internos de outro país, como argumentou a oposição venezuelana, pois atende à solicitação de um governo democraticamente eleito e está em conformidade com o direito internacional. Ao Brasil não interessava o caos político ou econômico em suas fronteiras (como já acontece em relação ao conflito na Colômbia), com um colapso da economia venezuelana ou uma guerra civil, que poderiam vir a ocorrer. Muito menos a quebra das regras constitucionais e a deposição de um governo eleito, o que já foi evitado com sucesso em mais de uma oportunidade pelo Mercosul em relação ao Paraguai.

Analisando a integração sul-americana e do Mercosul definidas como a principal prioridade, oferece-se aos vizinhos uma parceria necessária para retomar o crescimento da economia, condição indispensável para que a integração deixe de ser virtual, e para a possibilidade de uma ação estratégica no plano global que reverta à marginalização crescente que a região está sofrendo. Apenas a integração regional poderá garantir governabilidade e desenvolvimento para toda a América do Sul e ser um instrumento indispensável nas negociações da Alca.

Em retrospecto, a construção deste espaço sul-americano foi articulado durante o ano de 2003. A realização da XVII Reunião do Grupo do Rio, realizada em Cuzco, e a posse do presidente argentino Néstor Kirchner, que ocorreram na última semana de maio, representaram acontecimentos convergentes que sinalizam o retorno da diplomacia e da integração sul-americanas. O Grupo do Rio foi estabelecido em dezembro de 1986, como um Mecanismo Permanente de Consulta e Concertação Política, reunindo os membros do Grupo de Contadora (México, Venezuela, Colômbia e Panamá) e do Grupo de Apoio à Contadora (Brasil, Argentina, Peru e Uruguai), tentando propiciar aos países latino-americanos um espaço de atuação autônoma nas relações 
internacionais. A XVII reunião do Grupo foi importante, pois incorporou ao mecanismo diplomático o impacto da presença de um novo governo no Brasil e, dias depois, na Argentina.

Esta nova realidade permitiu reforçar a política lançada pelos países sulamericanos de desenvolver a infra-estrutura física (transporte, comunicação e energia), como forma de relançar o processo de integração. O presidente Toledo, do Peru, propôs que os credores internacionais dos países da região destinassem $20 \%$ do serviço da dívida às obras de infra-estrutura. O Brasil do presidente Lula, por seu turno, dá à iniciativa uma importância estratégica aprofundando qualitativamente a política esboçada pelo governo FHC em seu final. Assim, o Bndes já iniciou o financiamento de obras visando à integração física sul-americana e o assessor Marco Aurélio Garcia revelou que o governo pretende duplicar os recursos para o programa, bem como buscar apoio do BID e outros organismos financiadores.

Já o presidente Kirchner, revelou a vontade argentina de mudar a política econômica que o país desenvolveu nos últimos quatorze anos, abandonando o neoliberalismo e buscando um modelo baseado em investimentos públicos e combate à pobreza. No plano internacional, o novo presidente manifestou a intenção de estabelecer uma aliança estratégica com o Brasil, resgatar o Mercosul e cooperar ativamente para a integração sul-americana. Chama atenção que o novo governo argentino evoluiu das "relaciones carnales" de Menem com os EUA para uma atitude de eqüidistância, fazendo com que a Casa Branca comece a se preocupar com o surgimento de um pólo autônomo Brasil-Argentina.

Desta forma, o que se observa é o retorno da América do Sul ao protagonismo diplomático e ao processo de integração, com a afirmação paralela de agendas internas de desenvolvimento econômico e social. A atuação diplomática sul-americana, além disso, não se refere apenas ao plano regional, mas a uma atuação concertada de âmbito mundial. Em resumo, a anunciada associação do Peru ao Mercosul, a campanha por apoio dos países andinos à associação da Comunidade Andina de Nações ao Mercosul e o avanço concreto das medidas visando à integração da infra-estrutura física dos países sulamericanos criaram um clima novo na região. Novos governos assumiram o poder com posições internacionais comuns às da diplomacia brasileira, outros alteram sensivelmente suas agendas, convergindo com a do Itamaraty. Mes- 
mo a Colômbia, com a proposta brasileira de mediar a devolução de reféns em poder das Farc, parecem começar a ver o Brasil com outros olhos, e apenas o Chile persegue seu caminho afastado de seus vizinhos. Da mesma forma, as negociações com a União Européia voltaram a dar ao país uma dimensão multilateral e global em suas relações internacionais.

Outro marco da nova política externa foi a participação do presidente Lula na reunião do G7, em Evian, na França. O presidente, em nome da América do Sul, apresentou seu plano de combate à fome e a proposta de converter $20 \%$ do serviço da dívida em recursos para financiar obras de infraestrutura e relançar o desenvolvimento, além das habituais críticas ao protecionismo praticado pelos países ricos. Mas, como era de se esperar, o encontro reservado dos membros do Grupo pouca atenção deu a esta agenda (apesar dos elogios em público), concentrando-se na condenação ao terrorismo e na tentativa de encontrar caminhos para relançar a estagnada economia mundial. Nem isto, entretanto, foi conseguido, pois permaneceram os problemas ligados à agricultura e os temas do meio ambiente não foram debatidos, pois o presidente Bush rumou para o Oriente Médio.

Neste contexto o Brasil, para manter o protagonismo alcançado e contornar o pouco caso dos países ricos para com as necessidades e reivindicações do Terceiro Mundo, manteve contatos de alto nível e conseguiu criar o Grupo dos 3 (G-3), com a Índia e a África do Sul. Os chanceleres Celso Amorim, Yashwant Sinhá e Nkosazana Dlamini-Zuma anunciaram que o Grupo promoverá a cooperação trilateral, a liberalização comercial recíproca e a unificação e fortalecimento de posições nos foros multilaterais. As negociações envolverão o Mercosul, a União Aduaneira da África Austral e, possivelmente, a Saarc (Área de Cooperação Regional da Ásia Meridional). Os três países manifestaram, igualmente, o desejo de atrair a Rússia e a China para o Grupo em um segundo momento, transformando-o em G-5. ${ }^{2}$ A criação do G-3 constituiu uma iniciativa oportuna, no momento em que os países do Sul necessitam se mobilizar em defesa dos seus interesses e para alterar a atual agenda mundial.

2 Se isto ocorresse, o Grupo aglutinaria quase metade da população mundial e considerável parcela da produção do planeta, podendo influir significativamente nas negociações multilaterais. 
Um exemplo adicional do contínuo poder de mobilização da diplomacia do governo brasileiro foi a construção de outra aliança de "geometria variável", o G-20, que atuou de maneira eficiente na reunião da OMC em Cancun, que foi precedida por uma chamada telefônica do presidente Bush a Lula, o que é revelador. Cordial, mas contestadora, a diplomacia brasileira estabeleceu sua rede com os países em desenvolvimento afetados pelo protecionismo e pelos subsídios agrícolas do Primeiro Mundo. O chamado G-22 despertou a ira dos países ricos e fez a insatisfação do Sul ser ouvida, em meio ao encerramento espetacular do encontro. Assim, a tendência é a de que uma constelação sul-americana e de outras importantes potências (não exatamente um "bloco") venha a engrossar o apoio ao chamado "eixo da paz" (Paris-BerlimMoscou), como forma de moderar a postura norte-americana nas relações internacionais, simultaneamente contribuindo para a construção de um mundo multipolar regido pelo sistema das Nações Unidas.

Outras iniciativas a serem destacadas foram às visitas de Lula aos países árabes do Oriente Médio, como Líbia e Síria, e a aproximação com a África. A viagem que o presidente realizou na primeira semana de novembro, visitando São Tomé e Príncipe, Angola, Moçambique, Namíbia e África do Sul, cobriu os países de língua portuguesa da África austral e dois dos principais parceiros brasileiros da região, cumprindo a promessa. A visita foi importante não apenas para as relações do Brasil com a África, mas, sobretudo, para o estabelecimento de uma associação institucionalizada entre o Mercosul e a Sadc (Coordenação para o Desenvolvimento da África Austral), a área de integração nucleada pela África do Sul, na parte meridional do continente. ${ }^{3}$

\section{Conclusões}

Somados todos estes acontecimentos tem impactos nas relações do Brasil com os EUA e, certamente, nas negociações da Alca. Atualmente a Alca atravessa um momento decisivo e os presidentes Lula e Bush tem mantido encontros de alto nível, assim como contatos permanentes entre as diplomacias dos dois países. Estes contatos revelam certa margem de manobra pela parte brasileira, e o reconhecimento de um papel de liderança na América do Sul e na grande diplomacia.

3 Que também faz parte do G3 e mais articulações multilaterais da diplomacia brasileira. 
As manifestações do presidente Bush de que não estaria disposto a retirar os gigantescos subsídios agrícolas à agricultura americana e o protecionismo a produtos como o aço, devia-se à proximidade da eleição em 2004, bem como a medidas unilaterais destinadas a defender a economia americana. Subsídios, barreiras não-tarifárias, patentes, compras governamentais e outros itens seriam encaminhados para a OMC, e Bush teria uma sigla para exibir ao eleitorado americano. Na reunião da Alca, realizada em Port of Spain, os EUA deixaram claras estas posições. Porém, para os países do Mercosul, e o Brasil em particular, estes temas são fundamentais. E, da mesma forma, há questões na Alca que não lhes interessam, o que dificulta o processo.

Igualmente, o processo é dificultado por outras questões estruturais de hegemonia norte-americana, como o custo de suas decisões referentes à Guerra do Iraque. Com isso, a Casa Branca, frente às crescentes dificuldades nas negociações da Alca, necessita contar com o apoio brasileiro. Contudo, a Alca foi estabelecida no início de 2005, e dificilmente o será no formato proposto anteriormente, mas talvez uma Mini Alca ou Alca Light, que englobaria apenas temas comerciais. Concretamente, a reativação das economias americana e brasileira parece ser o objetivo imediato, como forma de facilitar o comércio. O grande problema é que, sem o apoio do Brasil, a Alca não será implementada, pois os EUA já têm acesso às economias dos demais países, que são de dimensões menores que a brasileira.

O governo Lula, por sua vez, começou a negociar mais firmemente, visando defender os interesses econômicos brasileiros. Como global trader, o país deseja manter suas relações com várias áreas do mundo, priorizando o Mercosul e a integração sul-americana. Depois de reverter às expectativas americanas de que o governo teria políticas esquerdistas, Lula passou a ser "admirado" em Washington. Mas é preciso observar que a diplomacia do Brasil, ao contrariar alguns desígnios da potência hegemônica e ressaltar sua autonomia, criou uma razoável margem de manobra. Assim, chamou atenção para suas reivindicações sócio-econômicas e para as obras de infra-estrutura com os vizinhos. Por outro lado, para enfrentar este inevitável e difícil diálogo entre opostos, a diplomacia brasileira preparou-se adequadamente, através de seu fortalecimento no mundo e na América do Sul.

Dessa forma, a diplomacia se apresenta como o campo mais bem sucedido do atual governo, com o país recuperando uma ação de grande intensidade e alcance planetário, digna da quinta nação mais populosa e extensa e da décima 
economia do mundo. Este protagonismo junto ao Terceiro Mundo e a diversificação dos vínculos com o Primeiro Mundo dão também ao país certo cacife para intensificar a campanha pela obtenção de um assento permanente no Conselho de Segurança da ONU reformado. Ironicamente, hoje o Brasil tem melhor diálogo com Washington e uma diplomacia mais respeitada, com capacidade de negociação.

Enfim, em termos de política externa, o Brasil alcançou resultados positivos nestes primeiros dois anos e meio de governo Lula, com uma diplomacia própria, adequada à era da globalização, e com um projeto de desenvolvimento para o país, que ainda se encontra bloqueado pela política econômica liberal ortodoxa do ministro Palocci e pela falta de uma correlação de forças favorável no plano interno. Ajustes internos e esquemas externos foram realizados para tanto, mas variáveis internacionais são importantes, pois o país depende ainda de um mundo muito instável para que este projeto dê resultados positivos. Sem um crescimento que gere empregos não conseguirá consolidar os avanços logrados na área sul-americana, base de nossa inserção internacional. A razão de a política externa ser à frente mais ousada do governo Lula reside no fato dela estar sendo dirigida pelo Itamaraty, que recuperou seu espaço e conta com o apoio de segmentos dentro do governo preocupados com a questão nacional, como o Bndes e as Forças Armadas.

\section{Referências}

ALMEIDA, Paulo Roberto de. Relações Internacionais e política externa do Brasil. Porto Alegre: Ed. da Universidade/Ufrgs, 1998.

AMORIN, Celso. Politica externa, democracia e desenvolvimento. Brasília: Funag/MRE, 1995.

ARAÚJO Jr., e outros. Brasil: o desafio da abertura econômica. Rio de Janeiro: Fundação Getúlio Vargas, 1992.

CERVO, Amado; BUENO, Clodoaldo. História da política exterior do Brasil. Brasília: UnB, 2002.

COSTA, Darc. Estratégia nacional: a cooperação sul-americana como caminho para a inserção internacional do Brasil. Porto Alegre: L\&PM Editores, 2004.

DANESE, Sérgio. Diplomacia presidencial. Rio de Janeiro: Topbooks, 1999.

FLORÊNCIO, Sérgio Abreu e Lima; ARAÚJO, Ernesto Fraga. Mercosul hoje. São Paulo: Alfa - Ômega, 1996. 
FONSECA Jr., Gélson; CASTRO, Sérgio Nabuco de (Org.). Temas de politica externa Brasileira II. São Paulo: Paz e Terra, 1994. 2 v.

GUIMARÃES, Samuel Pinheiro. Quinhentos anos de periferia. Porto Alegre: Ed. da Universidade/ Ufrgs/ Rio de Janeiro: Contraponto, 1999.

- (Org.). ALCA e Mercosul. Riscos e oportunidades para o Brasil. Brasília: Ipri-Funag/MRE, 1999.

LAFER, Celso. Mudam-se os tempos. Diplomacia Brasileira 2001-2002. Brasília: Ipri-Funag/MRE, 2002. (2 v.)

LAMPREIA, Luiz Felipe. Diplomacia Brasileira: palavras, contexto e razões. Rio de Janeiro: Lacerda Editores, 1999.

MINEIRO, Adhemar; ELIAS, Luiz Antonio; BENJAMIN, César (orgs). Visões da crise. Rio de Janeiro: Contraponto, 1998.

PANNUNZIO, Antonio, e outros. O Brasil no cenário internacional. São Paulo: Fundação Konrad Adenauer, 2000.

RABELO, Aldo; FERNANDES, Luis (Orgs). Politica externa brasileira para o século XXI. Brasília: Câmara dos Deputados, 2003.

2003.

RICUPERO, Rubens. Visões do Brasil. Rio de Janeiro: Record, 1995.

SENNES, Ricardo. As mudanças da politica externa brasileira nos anos 80: uma potência média recém industrializada. Porto Alegre: Ed. da Universidade/Ufrgs/ Nerint, 2003.

SILVA, Luiz Inácio Lula da; AMORIN, Celso; GUIMARÃES, Samuel Pineiro. A política externa do Brasil. Brasília: Ipri-Funag/ MRE, 2003.

VÁRIOS AUTORES. Reflexões sobre a politica externa brasileira. Brasília: IpriFunag/ MRE, 1993.

VIZENTINI, Paulo. Relações Internacionais do Brasil, de Vargas a Lula (19512002). São Paulo: Fundação Perseu Abramo, 2003.

. www.terra.com.br/vizentini

Carta Internacional, São Paulo: Nupri/ USP.

Contexto Internacional, Rio de Janeiro: IRI/ PUC-RJ.

Política Externa, São Paulo: Paz e Terra.

Revista Brasileira de Política Internacional, Rio de Janeiro/ Brasília: Ibri.

Recebido em 14 de junho de 2005 e aprovado em 20 de julho de 2005 